\title{
RISK REDUCTION IN TRANSPORT SYSTEM IN EMERGENCY CONDITIONS: A FRAMEWORK FOR NETWORK DESIGN PROBLEMS
}

\author{
ANTONINO VITETTA \\ Dipartimento di Ingegneria dell'Informazione, delle Infrastrutture e dell'Energia Sostenibile, \\ Università degli Studi Mediterranea di Reggio Calabria, Italy
}

\begin{abstract}
In emergency conditions, with dangerous events with effects delayed in the time, the transport supply requires configurations that allow the reduction of the negative effects on people. Therefore, it is necessary to define suitable design methodologies for risk reduction. In the context of the wider problem of the transport demand managing in all its components, this paper reports the problem for the road network design in transport systems. The problem analysed considers the design of the link directions and the traffic light regulation at the junction in the road networks for users and emergency vehicles. The paper: reports a state of the art of the problem; introduces a general framework; formulates the problem in terms of aggregate mathematical models. For further information on the topics reported, the literature cited can be considered.
\end{abstract}

Keywords: emergency condition, network design problem, vehicle routing problem, risk reduction.

\section{INTRODUCTION}

In the presence of natural or manmade disasters with effect on the people delayed in the time, the transport system must work at its best in order to allow the evacuation of users in the shortest possible time. Considering the three components of the risk, occurrence, vulnerability and exposure, with this type of events, the application of design methodologies for exposure reduction is fundamental (for more details see Fig. 1 cited in the Section 3 of this paper and the connected comments).

The design methodologies require the definition of different components of the transport system:

- the evacuation planning [1];

- the evacuation training [2], [3];

- the risk assessment and management [4];

- the analysis of the demand for mobility in terms of user behaviour [5];

- the study of the performance of the supply model in terms of disutility for users [6];

- the interactions between supply and demand models [7]-[9];

- the evaluation methods [10], [11].

The study of these components is beyond this paper scope.

This paper deals with some design methodologies with the assumption that the interaction between supply and demand is considered as a behaviour constraint of the optimum model. These methodologies can be used in the planning phase of the short or long term in the design of the best configuration of the supply system for risk reduction.

Among all the design models, the goal of this paper is to report a brief state of the art and to formulate the models commonly used to address the following problems: design of the link directions and the traffic light regulation at the junction in the road networks to be used by users and emergency vehicles (network design problem (NDP)). 
Following this approach, the paper is divided into the following sections: Section 2 contains the state of the art for NDP; Section 3 reports a general framework of the method; Section 4 contains the formulations for the NDP. Finally, Section 5 reports some conclusions.

\section{STATE OF THE ART}

The NDP consists in defining the optimal configuration of the road and transit transport network in terms of topology and capacity. In the case of transport systems in emergency conditions, the NDP refers to the road transport system because transit transport vehicles are used and designed in emergency with VRP (vehicle routing problem) procedures reported in other papers, i.e. [12], [13].

The design of the topology consists in defining the optimal configuration of the directions and the allocation of the lanes in the road links. The allocation of the lanes involves the definition of the capacity of the links in each direction. One of the first papers concerning the road network topology design has been proposed in Chen and Alfa [14]. Other design methods have been proposed for the generation of optimal topological configurations under ordinary conditions, i.e. [15], [16]. The problem has been studied by numerous authors. Among all the papers proposed, some examples of methods for the design of the road network in ordinary conditions are cited, i.e. [17]-[20].

The road design problem has been extended to the emergency conditions. A method for vehicle assignment in emergency condition is reported in Kalafatas and Peeta [21]; a method for planning evacuation is reported in He et al. [22]; a method for contraflow operation is reported in Webster [23].

The design of the capacity consists in defining the optimal configuration of the regulation parameters at road intersections with methods valid for traffic light and priority junctions. The priority junctions, can be treated from a model point of view as the signalized junctions with appropriate mathematical analogies. Numerous methods have been proposed for the design of traffic light regulation in ordinary conditions. Some methods proposed are cited for single junctions, i.e. [24], [25] and interacting junctions, i.e. [26]-[29].

In ordinary conditions the topology and the capacity are studied inside the same model with the solution adopting heuristic procedures, i.e. [30].

In the SICURO project a general formulation for the risk has been proposed [4] the problem of the link topology design and the light regulation of the junctions has been studied under emergency conditions by experimentation, i.e. [31]-[34].

\section{FRAMEWORK}

The overall framework regarding NDP in emergency conditions is shown in Fig. 1.

\section{$3.1 \mathrm{~A}$}

The main part of the NDP is the risk reduction model (A in Fig. 1). This model takes as input:

- the occurrence values of the calamitous event and the vulnerability of the supply system (B in Fig. 1);

- the risk reduction objectives (C in Fig. 1);

- external and technical constraints (D in Fig. 1);

- the consistency between demand, flows and costs, which is also called behavioural constraint (from $\mathrm{E}$ to $\mathrm{N}$ in Fig. 1);

and it provides as output the configurations of the supply model in terms of topology of links and capacity at junctions (O in Fig. 1). 


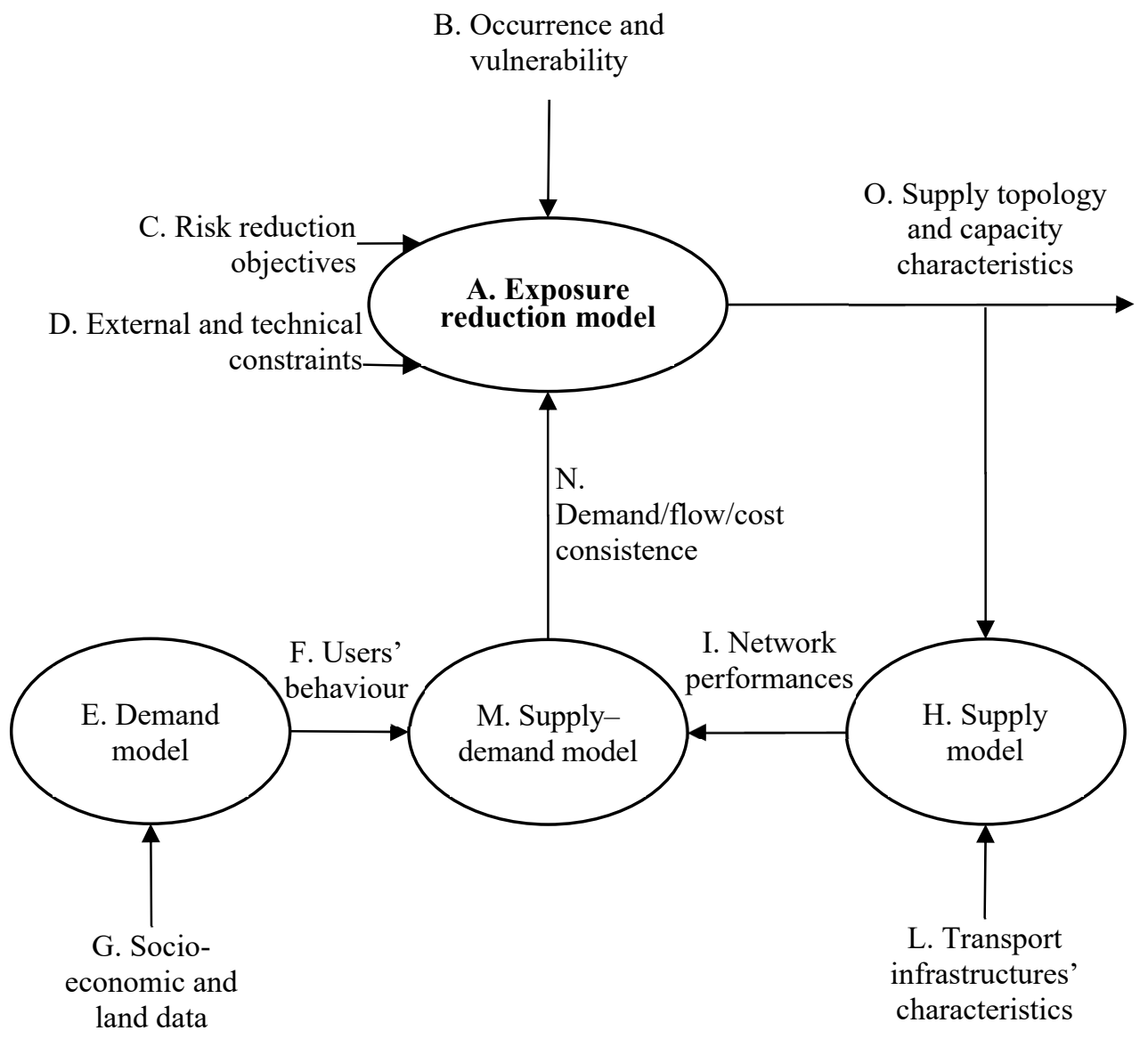

Figure 1: General framework.

\section{$3.2 \mathrm{~B}$}

The risk function is assumed to consist of three components: occurrence, vulnerability and exposure [4]. Each component is defined by a probability with the exception of the social risk case where the exposure is defined by a quantity in term of people. In the case of the transport network design, it is assumed that the first two components (B in Fig. 1) are defined a priori (it is the case of the occurrence of calamitous events in a transport system with predefined vulnerability). Therefore, the reduction of risk, in this case, coincides with the exposure reduction (A in Fig. 1).

\section{$3.3 \mathrm{C}$}

The risk reduction in this specific case coincides with the reduction of exposure, which is implemented with evacuation measures. Evacuation has the purpose of making people move 
away and therefore reduces the number of people present in the system when the calamitous event generates effects in the system ( $\mathrm{C}$ in Fig. 1). The objectives to be pursued with the reduction of exposure are mainly of two types: to minimize the evacuation time of the last user who leaves the system from the areas at risk; evacuate all people from the dangerous area (or, if it is not possible, maximizing the number of people evacuated before the dangerous effects).

\section{$3.4 \mathrm{D}$}

The external and technical constraints must be respected and that cannot be modified with the project (D in Fig. 1). Some examples of technical constraints are for example the number of emergency vehicles available, the size of the safe areas. Some examples of external constraints are laws, regulations and guidelines.

\section{$3.5 \mathrm{E}-\mathrm{N}$}

The behavioural constraint models represents the users choice in the transport system on different levels and it is non-linear. The best choice to users can be recommended and it is difficult to force each user to make the choice. Therefore it is necessary:

- to build a demand model (E in Fig. 1) that models user behaviour (F in Fig. 1) starting from socio-economic data (G in Fig. 1);

- $\quad$ to build a supply model (H in Fig. 1); it models the performance of the system (I in Fig. 1) starting from transport infrastructure characteristics; it should be noted that the supply model has also input the supply topology and capacity characteristics ( $\mathrm{O}$ in Fig. 1), output of the design model and which will be reported in the next paragraph $(\mathrm{O})$;

- to build a model of interaction between supply and demand (M in Fig. 1) which provides as output the consistency between demand, flow and costs ( $\mathrm{N}$ in Fig. 1) and takes as input the behaviour of users and network performances.

\section{$3.6 \mathrm{O}$}

The model gives as outputs the topological and capacity configuration of the network $(\mathrm{O}$ in Fig. 1). It should be noted that the output of the design model is also the input of the behavioural constraint, that is of a non-linear type. For this reason, heuristic procedures [30] must be applied to solve the problem in real size transport systems.

\section{MODEL}

The NDP in a general form can be specified in the following form:

$$
\left\{\begin{array}{rll}
\begin{array}{l}
\text { Minimum } y \\
\text { Subject to: }
\end{array} & \phi(\mathbf{y}, \mathbf{f}) & \left(\mathbf{y}^{*} \text { is the optimal value of } \mathbf{y}\right) \\
\mathbf{y} \in \psi_{\boldsymbol{E} T \boldsymbol{y}} ; \quad \mathbf{f} \in \psi_{\boldsymbol{E} T \boldsymbol{f}} & \text { (external and technical constraints) } \\
\mathbf{f}=\boldsymbol{\xi}(\mathbf{f}, \mathbf{y}) ; \quad \mathbf{f} \in \psi_{\boldsymbol{B} \boldsymbol{f}} & \text { (behavioural constraints) }
\end{array}\right.
$$


The output (O in Fig. 1) of the design model is given by the value $\mathbf{y}^{*}$ of the vector $\mathbf{y}$ which minimizes the objective function $\phi(\bullet)$. The vector $\mathbf{y}$ contains the design variables that define the topological configuration of the network (discrete variables) and the light regulation strategy at junctions (continuous variables).

The objective function (minimum $\phi(\mathbf{y}, \mathbf{f})$ ) models risk reduction (C in Fig. 1). Considering that the occurrence and the vulnerability are predefined (B in Fig. 1) in this specific case of evaluation, the objective function (A in Fig. 1) is the reduction of the probability of presence of people (individual risk) or of the total number of people (social risk) in the areas at risk. Therefore the objective function can consider one of the following two criteria:

- minimum of the total evacuation time of all users;

- evacuate all people from the dangerous area or, if it is not possible, maximizing the number of people evacuated in a pre-established time and generally coinciding with the expected time of production of the negative effects on users.

The technical and external constraints ( $D$ in Fig. 1) can be indicated by belonging to the vectors $\mathbf{y}$ and $\mathbf{f}$ to the respective feasibility sets $\psi_{E T y}$ and $\psi_{E T f}\left(\mathbf{y} \in \psi_{E T y} ; \mathbf{f} \in \psi_{E T f}\right)$. Very often these constraints are defined with linear inequalities (e.g. number of lanes lower than and equal to a predetermined value; number of vehicles available minimum or equal to a predetermined value).

The behavioral constraint $\left(\mathbf{f}=\Psi_{f}(\mathbf{f}, \mathbf{y})\right)$ considers the choice of users that follows the maximum of his utility (from $\mathrm{E}$ to $\mathrm{N}$ in Fig. 1). Therefore behavior must be modeled using established approaches in transport engineering [35]. The result of the users' choice is the flows vector $\mathbf{f}$ and the network performances. Each element of the vector $\mathbf{f}$ models the flow of users in each link of the network. Random utility models typically is applied.

In a static context (which does not well represent the system in emergency conditions), the behavioral constraint can be expressed as:

$$
\mathbf{f}=\Delta(\bullet) P(\bullet) d(\bullet)
$$

where

- $\Delta(\bullet)=\Delta(\mathrm{y})$ the link-path incidence matrix; it depends on $\mathrm{y}$;

- $\mathrm{P}(\bullet)=\mathrm{P}\left(\Delta(\bullet)^{\prime} \Gamma(\bullet), \mathrm{y}\right)$ the path choice-origin destination pairs matrix; it depends on the path cost $\Delta(\bullet)^{\prime} \Gamma(\bullet)$ and $\mathrm{y}$;

- $\mathrm{d}(\bullet)=\mathrm{d}\left(\Delta(\bullet)^{\prime} \Gamma(\bullet), \mathrm{y}\right)$ the demand vector for the origin destination pairs; it depends on the path cost $\Delta(\bullet)^{\prime} \Gamma(\bullet)$, and y;

- $\Delta(\bullet)^{\prime} \Gamma(\bullet)=\Delta(\mathrm{y})^{\prime} \Gamma(\mathrm{f}, \mathrm{y})$ the path cost vector;

- $\quad \Gamma(\bullet)=\Gamma(\mathrm{f}, \mathrm{y})$ the link cost functions vector; it depends on $\mathrm{f}$ and $\mathrm{y}$.

It is the results of the interaction between demand models (represented by means $P(\bullet)$ and $\boldsymbol{d}(\bullet)$ and their relations) and supply models (represented by $\Delta(\bullet)$ and $\Gamma(\mathbf{f}, \mathbf{y})$ and their relations).

In emergency conditions the dynamic approach better represent the users' behavior. Two approaches can be adopted: within-day and/or day-to-day models [35].

In both cases, a compact representation can be adopted:

$$
\mathbf{f}=\xi(\mathbf{f}, \mathbf{y})
$$

In both cases the flow belongs to the flow feasible set $\psi_{B f}$.

$$
\mathbf{f} \in \psi_{B \boldsymbol{B}}
$$




\section{CONCLUSIONS}

In this paper a model for the urban road transport network design has been reported. The model has been considered in the wider problem of risk reduction and, in particular, exposure reduction in presence of calamitous events. The quantitative design models is required in order to optimize the system in a preventive way and therefore be ready to allow optimal evacuation of users.

The main novelty reported in this paper concerns the specification of a model for the road transport networks design; it could be used for planning transport systems in emergency conditions. The design model has been reported in a unitary approach, starting from the state of the art. It is linked to the three components of risk: occurrence, vulnerability, exposure. The objective function was considered as a quantitative indicator of the risk exposure component in order to link network design and risk areas. The overall model has been specified also considering the behavioural constraint that models the choices of the users. The behavioural constraint is not linear and the design variables are continuous and integers. Therefore the problem requires the use of heuristic solution algorithms.

The methodologies proposed in this paper can be used for the medium or long-term design of the links layout and junctions regulation of a road network, aimed at reducing the risk. The optimal design of the transport network, especially in emergency conditions, would reduce the time required for the evacuation of users. Therefore, this methodology is a decision support that must be taken into account by operators in emergency conditions. The application of the methods reported cannot be implemented in real time. An emergency situation generates wide and differentiated management problems and scenarios. Therefore the design methods must be specified, calibrated and validated in advance using hypothetical risk scenarios. In real situations, the results and models obtained previously can be updated with changes in the real scenario compared to those assessed a priori; it could be considered as a decision support system. Therefore, for the application of these models, a preventive planning activity is required, including training.

In the future, the framework and the models reported require an extensive activity of specification-calibration-validation in real contexts followed by continuous training on the various components involved (system managers, operators, users, citizens).

\section{ACKNOWLEDGEMENTS}

This research is partially supported by the Dipartimento di ingegneria dell'Informazione, delle Infrastrutture e dell'Energia Sostenibile, Università Mediterranea di Reggio Calabria, and by the project "La Mobilità per i passeggeri come Servizio - MyPasS", Fondi PON R\&I 2014-2020 e FSC “Avviso per la presentazione di Progetti di Ricerca Industriale e Sviluppo Sperimentale nelle 12 aree di Specializzazione individuate dal PNR 2015-2020", codice identificativo ARS01_01100.

\section{REFERENCES}

[1] Russo, F. \& Rindone, C., Safety of users in road evacuation: Planning internal processes and guidelines. WIT Transactions on The Built Environment, vol. 96, WIT Press: Southampton and Boston, pp. 825-834, 2007.

[2] Russo, F., Rindone, C. \& Trecozzi, M.R., The role of training in evacuation. WIT Transactions on Information and Communication Technologies, vol. 44, WIT Press: Southampton and Boston, pp. 491-502, 2012. 
[3] Russo, F. \& Rindone, C., Urban exposure: Training activities and risk reduction. WIT Transactions on Ecology and the Environment, vol. 191, WIT Press: Southampton and Boston, pp. 991-1001, 2014.

[4] Russo, F. \& Vitetta, A., Safety of users in road evacuation: General methodology and main results. WIT Transactions on the Built Environment, vol. 96, WIT Press: Southampton and Boston, pp. 763-772, 2007.

[5] Russo, F. \& Chilà, G., Safety of users in road evacuation: RP vs. SP surveys in demand analysis. 14th International Conference on Urban Transport and the Environment in the 21st Century, pp. 703-713, 2008.

[6] Musolino, G. \& Vitetta A., Short-term forecasting in road evacuation: Calibration of a travel time function. WIT Transactions on the Built Environment, vol. 116, WIT Press: Southampton and Boston, pp. 615-626, 2011.

Di Gangi, M., Planning evacuation by means of a multi-modal mesoscopic dynamic traffic simulation model. Studies in Computational Intelligence, 176, pp. 99-115, 2009. DOI: 10.1007/978-3-540-89930-3_6.

[7] Di Gangi, M., Safety of users in road evacuation: Modelling and DSS for pedestrian outflow. WIT Transactions on Ecology and the Environment, vol. 120, WIT Press: Southampton and Boston, pp. 497-508, 2009. DOI: 10.2495/SDP090461.

[8] Di Gangi, M., Watling, D. \& Di Salvo, R., Modeling evacuation risk using a stochastic process formulation of mesoscopic dynamic network loading. IEEE Transactions on Intelligent Transportation Systems, 2020.

[9] Russo, F. \& Rindone, C., Safety of users in road evacuation: the logical framework approach in evacuation planning. 14th International Conference on Urban Transport and the Environment in the 21st Century, pp. 751-760, 2008.

[10] Russo, F. \& Rindone, C., The planning process and logical framework approach in road evacuation: A coherent vision. WIT Transactions on The Built Environment, vol. 117, WIT Press: Southampton and Boston, pp. 415-425, 2011.

[11] Vitetta, A., Polimeni, A. \& Quattrone, A., Safety of users in road evacuation: Modelling and DSS for paths design of emergency vehicles. WIT Transactions on Ecology and the Environment, vol. 120, WIT Press: Southampton and Boston, pp. 485-495, 2009.

[12] Polimeni, A. \& Vitetta A., The role of ITS in evacuation route optimization for emergency vehicles. WIT Transactions on Information and Communication Technologies, vol. 44, WIT Press: Southampton and Boston, pp. 517-529, 2012. DOI: $10.2495 /$ RISK120431.

[13] Billheimer, J.W. \& Gray, P., Network design with fixed and variable cost elements. Transport. Sci., 7, pp. 49-74, 1973.

[14] Chen, M. \& Alfa, A.S., A network design algorithm using a stochastic incremental traffic assignment approach. Transport. Sci., 25, pp. 215-224, 1991.

[15] Foulds, L.R., A multi-commodity flow network design problem. Transportation Research Part B, 15, pp. 273-283, 1981.

[16] Herrmann, J.W., Ioannou, G., Minis, I. \& Proth, J.M., A dual ascent approach to the fixed-charge capacitated network design problem. European Journal of Operational Research, 95, pp. 476-490, 1996.

[17] Solanky, R.S., Gorti, J.K. \& Southworth F., Using decomposition in large-scale highway network design with a quasi-optimization heuristic. Transportation Research Part B, 32(2), pp. 127-140, 1998.

[18] Gao, Z., Wu J. \& Sun, H., Solution algorithm for the bi-level discrete network design problem. Transportation Research Part B, 39, pp. 479-495, 2005. 
[19] Poorzahedy, H. \& Rouhani, O.M., Hybrid meta-heuristic algorithms for solving network design problem. European Journal of Operational Research, 182(2), pp. 578596, 2007.

[20] Xie, C. \& Turnquist, M.A., Integrated evacuation network optimization and emergency vehicle assignment. Transportation Research Part B, 2009.

[21] Kalafatas, G. \& Peeta, S., Planning for evacuation: Insights from an efficient network design model. Journal of Infrastructure Systems, 15(1), pp. 21-30, 2009.

[22] He, X., Zheng H., Peeta S. \& Li Y., Network design model to integrate shelter assignment with contraflow operations in emergency evacuation planning. Networks and Spatial Economics, 18(4), pp. 1027-1050, 2018.

[23] Webster F.V., Traffic signal settings. Road Research Technical Paper No. 39, Road Research Laboratory: London, 1958.

[24] Allsop, R.E., SIGSET: A computer program for calculating traffic capacity of signal controlled road junctions. Traffic Eng. Control, 12, pp. 58-60, 1971.

[25] Little, J.D.C., Kelson, M.D. \& Gartner, N.H., MAXBAND: A program for setting signals on arteries and triangular networks. Transportation Research Record, 795, pp. 40-46, 1981.

[26] Robertson D.I., TRANSYT method for area traffic control. Traffic Engineering and Control, 10, pp. 276-281, 1969.

[27] Little, J.D.C., The synchronisation of traffic signals by mixed-integer-linearprogramming. Operations Research, 14, pp. 568-594, 1966.

[28] Cantarella, G.E., Improta, G. \& Sforza, A., Road network signal setting: Equilibrium conditions. Concise Encyclopaedia of Traffic and Transportation Systems, ed. M. Papageorgiou, Pergamon Press, pp. 366-371, 1991.

[29] Cantarella, G.E., Pavone, G. \& Vitetta, A., Heuristics for urban road network design: Lane layout and signal settings. European Journal of Operational Research, 175(3), pp. 1682-1695, 2006.

[30] Marcianò, F.A, Musolino, G. \& Vitetta A., Signal setting design on a road network: Application of a system of models in evacuation conditions. WIT Transactions on Information and Communication Technologies, vol. 43, WIT Press: Southampton and Boston, pp. I443-I454, 2010.

[31] Marcianò, F.A., Musolino, G. \& Vitetta, A., A system of models for signal setting design of a signalized road network in evacuation conditions, WIT Transactions on the Built Environment, vol. 111, WIT Press: Southampton and Boston, pp. 313-323, 2010.

[32] Marcianò, F.A., Musolino, G. \& Vitetta, A., Within-day traffic assignment and signal setting in road evacuation: A procedure with explicit path enumeration, WIT Transactions on the Built Environment, vol. 117, WIT Press: Southampton and Boston, pp. 403-414, 2011.

[33] Marcianò, F.A, Musolino, G. \& Vitetta A., Signal setting optimization on urban road transport networks: The case of emergency evacuation. Safety Science, 72, pp. 209220, 2015.

[34] Cascetta, E., Transportation Systems Engineering: Theory and Methods, Springer: New York, 2009. 